\title{
Correction to: Contextual modulation of prime response retrieval processes: Evidence from auditory negative priming
}

\author{
Susanne Mayr ${ }^{1} \cdot$ Malte Möller $^{1}$ - Axel Buchner ${ }^{2}$
}

Published online: 5 September 2018

(C) The Psychonomic Society, Inc. 2018

\section{Correction to: Attention, Perception, \& Psychophysics https://doi.org/10.3758/s13414-018-1574-z}

The Publisher regrets that two erroneous values were introduced by the typesetter when performing proof corrections. The first error occurred in the second paragraph of the "Design" section of Experiment 1:

" $\rho=.04 "$ should be " $\rho=.4 "$.

The second error occurred at the very end of the "Experiment 1 " section in the "Appendix":

“ $d_{\mathrm{z}}=.010$ " should be " $d_{\mathrm{z}}=0.10$ ".

The original article has been corrected.

The online version of the original article can be found at https://doi.org/ 10.3758/s13414-018-1574-z

Susanne Mayr

susanne.mayr@uni-passau.de

1 Psychology and Human-Machine Interaction, Universität Passau, 94032 Passau, Germany

2 Heinrich-Heine-Universität Düsseldorf, Düsseldorf, Germany 